\title{
Bonus or Mirage? South Africa's Demographic Dividend
}

Morné J. Oosthuizen ${ }^{\mathrm{a}}$

${ }^{\text {a }}$ Development Policy Research Unit, School of Economics, University of Cape Town

Postal address:

Development Policy Research Unit

School of Economics

University of Cape Town

Private Bag X3

Rondebosch, 7701

SOUTH AFRICA

Contact Details:

Email: Morne.Oosthuizen@uct.ac.za

Tel: +27 216505705 


\begin{abstract}
South Africa is in the process of undergoing a demographic transition and the population is currently ageing. Within the next three decades, the median age is expected to rise from 25 years to 31 years. As part of this process, the changing age structure of the population gives rise to the demographic dividend. This dividend represents a potential boost to per capita incomes that countries can only access in the presence of a supportive policy context. However, South Africa is still dealing with the consequences of apartheid-era socioeconomic policies and has already progressed through a significant proportion of the first demographic dividend period. Using the National Transfer Accounts approach and data for 2005, this paper investigates the extent of the remaining portion of the first demographic dividend and assesses the prospects for capturing the potentially more significant second dividend.
\end{abstract}

\title{
Keywords:
}

National Transfer Accounts, demographic dividend, economic lifecycle, South Africa

\section{Introduction}

South Africa is in the process of undergoing a demographic transition. While close to half of the country's population is under the age of 25 , the population is ageing: the median age has risen from 18 years to 25 years over the past three decades and is projected to rise to 31 over the next three decades (own calculations, United Nations, 2013b). The transition from high fertility and high mortality, to low fertility and low mortality results in a transitory shift in the composition of the population until a new steady state is achieved. Specifically, since mortality declines before fertility, the demographic transition creates a boom generation: a series of cohorts that are unusually large. As fertility declines and these large cohorts enter the working ages, there is a decline in the extent to which the average worker is relied upon by nonworkers (children and the elderly in particular) for their consumption. This fall in economic dependency releases resources that can be used to raise living standards, to invest or to save. This is the demographic dividend. 
However, 20 years after the system's demise, South Africa still bears the scars of apartheid. South Africa's highly unequal society is reflected in its economy, in which a sophisticated modern sector with high incomes exists alongside a low-income informal sector. Although economic growth in the post-apartheid era has generally been significantly higher - and more stable - than growth in the preceding two decades, it has been insufficient to draw the unemployed in significant numbers into productive employment. As a result, unemployment, poverty and inequality remain three of the most pressing socioeconomic issues facing the country. The narrow unemployment rate in 2014 is estimated at 25.2 percent, while including the nonsearching unemployed raises this to 35.1 percent (own calculations, Statistics South Africa, 2014b). Latest estimates put 45.5 percent of the population below the national poverty line in 2011 (Statistics South Africa, 2014a), and South Africa's Gini coefficient of 0.631 in 2009 made it the most unequal country in the world (amongst all countries with data between 2009 and 2011) by this measure (World Bank, 2013).

The process of population ageing and the associated demographic dividend therefore represents an important opportunity for South Africa. However, the demographic dividend is not a guaranteed benefit and, given its social and economic challenges, South Africa risks failing to capitalise on this dividend. Indeed, many of the socioeconomic problems facing the country actively work against the realisation of the dividend. This paper explores the possibility of the demographic dividend in South Africa by estimating its potential size and exploring some of the factors that may enhance or constrain the country's ability to capture the dividend in the future.

\section{Demographic Dividends and National Transfer Accounts}

The demographic transition sees a society move from an equilibrium characterised by high fertility and high mortality, to one characterised by low fertility and low mortality. In the initial stages of the transition, mortality falls first and particularly so amongst children (Bloom et al., 2000, p.258). Improved survival amongst young cohorts creates a boom generation and a surge in the population growth rate as parents take time to adjust their fertility decisions. Child dependency rates rise and populations become younger on average. However, once fertility decisions are adjusted downwards to account for lower mortality, the population growth rate falls and the mean age of the population begins to rise. As the large cohorts enter the 
working ages, the working-age population grows relative to the total population and child dependency ratios fall. The final stage of this transition includes a surge in the size of the elderly population as large cohorts reach retirement age, forcing up the oldage dependency ratio.

The demographic transition can boost economic growth in two broad ways. First, as the dependency ratio falls and the working-age population grows relative to the total population, the average number of children per working-age adult declines too. Ceteris paribus, this is associated with a freeing up of resources that previously would have been consumed by additional children, allowing living standards to rise. This is the first demographic dividend.

This first demographic dividend is distinguished from a second dividend by Mason and Lee (2007, p.4). Rising longevity results in increased demand for lifecycle wealth as working age cohorts are faced with extended periods of retirement, during which they are economically dependent and reliant on either their own accumulations of savings or transfers from the state or from their families. Thus, working-age cohorts increasingly accumulate wealth to support themselves during old age, a process facilitated by lowered fertility. At the same time, with fewer children, working-age cohorts are able to invest more in the education and health of their offspring. This accumulation of financial and human capital, through capital deepening and higher incomes, may permanently raise incomes (Mason and Lee, 2006, p.15). $\square$ Typically, the demographic dividend has been modelled in terms of dependency ratios and the proportion of the population who are of working age. For example, Bloom et al. (2003) rely on these metrics in describing the processes that drive the demographic dividend. A more nuanced approach, however, should arguably take into account differences in productivity at different ages as well as differences in consumption needs. Further, the age cut-offs used in dependency ratios are arbitrary, as Mason and Lee (2007) note, and do not allow for cross-country differences in labour market engagement. While data on these age-specific differences has generally been difficult to obtain and not necessarily consistently constructed across different countries, the National Transfer Accounts (NTA) framework provides a consistent methodology to construct such estimates.

The NTA framework focuses on what is referred to as the generational economy, 
which is defined as: (1) the social institutions and economic mechanisms used by each generation or age group to produce, consume, share, and save resources; (2) the economic flows across generations or age groups that characterize the generational economy; (3) explicit and implicit contracts that govern intergenerational flows; (4) the intergenerational distribution of income or consumption that results from the foregoing (Lee and Mason, 2011, p.7). There are four activities that are central to the generational economy, namely working, consuming, sharing and saving (Mason and Lee, 2011, p.7). Consumption occurs throughout the lifecycle, although the level varies by age. Working, however, does not occur across all ages, particularly amongst the very young and the very old. As a result, the young and old are typically unable to finance their consumption on their own. Sharing and saving, then, represent the only means through which the young and old are able to bridge this gap.

The key technical aim of NTA is the quantification of economic flows for single-year age cohorts. For any individual, inflows must equal outflows: individuals can receive resources in the form of labour income $\left(Y^{l}\right)$, asset income $\left(Y^{A}\right)$ and transfers from others $\left(\tau^{+}\right)$, and can use them in consumption $(C)$, transfers to others $\left(\tau^{-}\right)$and savings $(S)$. Rearranging the terms, the NTA is governed by the following identity for each age cohort $(x)$, first presented by Lee (1994):

$$
C(x)-Y^{l}(x)=\tau^{+}(x)-\tau^{-}(x)+Y^{A}(x)-S(x)
$$

In other words, the lifecycle deficit $\left(C(x)-Y^{l}(x)\right)$ equals net transfer inflows $\left(\tau^{+}(x)-\tau^{-}\right.$ (x)) plus asset-based reallocations $\left(Y^{A}(x)-S(x)\right)$. This identity holds true at the individual level, at the cohort level and in the aggregate.

NTA estimates of intergenerational resource flows address some of the concerns raised regarding the use of dependency ratios in analysing the demographic dividend. The age profile of per capita labour income incorporates the effects of age-related differences in labour market participation, unemployment, productivity and hours worked, amongst other factors, and has no explicit age cut-offs. Similarly, the shape of the consumption age profile reflects the changing level of consumption at different ages.

The demographic dividends are formalised by Mason and Lee (2006). The effective number of producers $(L)$ and the effective number of consumers $(N)$ are defined as 
$L(t)=\int \gamma(x) P(x, t) d x$ and $N(t)=\int \phi(x) P(x, t) d x$ respectively, where $\gamma(x)$ represents age-specific variations in productivity, $\phi(x)$ represents age-specific variations in consumption and $P(x, t)$ is the population of age $x$ in year $t$. Income per effective consumer, $y(t)=Y(t) / N(t)$, can therefore be expressed as the product of two factors:

$$
\begin{aligned}
& Y(t) / N(t)=L(t) / N(t) \times Y(t) / L(t) \\
& y(t)=S R(t) \times y_{l}(t)
\end{aligned}
$$

where $S R(t)$ is the support ratio and $y_{l}(t)$ is mean income per worker.

The support ratio relates the number of effective workers to the number of effective consumers. Changes in the population structure that raise the support ratio imply a greater proportion of the population in more productive cohorts and, therefore, income per effective consumer rises, ceteris paribus. Mean income per worker is influenced by numerous factors - broadly incorporating capital, technology, and institutions - as well as income from foreign assets in the case of open economies (Mason and Lee, 2006, p.13).

In terms of growth rates, equation 2 can be expressed as $\dot{y}(t)=\dot{S R}(t)+y_{l}(t)-$ growth in income per effective consumer is the sum of growth in the support ratio and growth in income per worker - while growth in the support ratio is the difference between growth in the number of effective producers and growth in the number of effective consumers, or $\dot{S R}(t)=\dot{L}(t)-\dot{N}(t)$. The first demographic dividend is defined as the rate of growth of the support ratio, which is positive in contexts where the number of effective producers grows more rapidly than the number of effective consumers.

This paper uses data from the 2005 National Transfer Accounts for South Africa to analyse the demographic dividends. This rich data source allows the calculation of the support ratio, using detailed age profiles of labour income and consumption and population estimates and projections. The construction of the accounts requires a wide variety of data, including household surveys, administrative data and national accounts data. Full details of the methodology for constructing the accounts can be found in United Nations (2013a). The construction of the 2005 NTA age profiles for 
South Africa relies principally on the nationally representative 2005/06 Income and Expenditure Survey (IES) conducted by Statistics South Africa. Two other household surveys - the September 2005 Labour Force Survey and 2005 General Household Survey - are utilised where the IES did not have the required information. Aggregate control totals are calculated from the South African Reserve Bank's national accounts data (South African Reserve Bank, 2013) and national and provincial budget documents.

\section{The Economic Lifecycle in South Africa}

Figure 1 presents the 2005 per capita labour income, consumption and lifecycle deficit age profiles for South Africa. As is convention in NTA analyses, each of the flows has been normalised by dividing through by the simple average of per capita labour income amongst 30 to 49 year olds. In addition to the profiles for South Africa, the interquartile ranges for normalised labour income and consumption profiles across all NTA countries are plotted. ${ }^{1}$

$$
<<\text { Figure } 1 \text { about here }>>>
$$

$\ll$ Figure 1: Labour income, consumption and the lifecycle deficit, 2005 >>

$<<$ Source: Own calculations, National Transfer Accounts (2013). >>>

A key feature of the South African labour income profile is its slow increase amongst young people relative to other countries for which there is data. Labour income for 25 year olds is just 41.6 percent of peak labour income, of which 94 percent is derived from employment and the remaining 6 percent from self-employment. This late rise in labour income is the result of very low levels of engagement in the labour market

\footnotetext{
${ }^{1}$ Estimates from 33 other NTA countries are used. These countries are: Argentina (1997), Australia (2004), Austria (2005), Brazil (2002), Chile (1997), China (2002), Colombia (2008), Costa Rica (2004), Finland (2004), France (2001), Germany (2003), Hungary (2005), India (2004), Indonesia (2005), Italy (2008), Jamaica (2002), Japan (2004), Kenya (2005), Mozambique (2008), Nigeria (2009), Peru (2007), Philippines (1999), Senegal (2005), Slovenia (2004), South Korea (2000), Spain (2000), Sweden (2003), Taiwan (2003), Thailand (2004), United Kingdom (2010), Uruguay (2006), United States of America (2003) and Vietnam (2008). Labour income and consumption profiles are normalised by dividing values by mean labour income amongst 30 to 49 year olds - referred to here as 'peak labour income' - in each respective country.
} 
amongst young South Africans. In 2005, the expanded unemployment rate - which includes amongst the unemployed the non-searching unemployed - was estimated at 65 percent amongst 15 to 24 year olds and 42 percent amongst 25 to 34 year olds in 2005 (own calculations, Statistics South Africa, 2006). With just 14 percent of 15 to 24 year olds employed, South African normalised per capita labour income for 24 year olds is comparable to that of 21 year olds in the median NTA country.

Despite this late rise, normalised labour income remains above one until relatively late, but declines rapidly thereafter, falling from the top quartile to the third quartile in the space of around ten years. So, while the South African labour income profile is very similar in gradient to those of other countries at young working ages - albeit delayed by around three years - amongst older working-aged adults it falls significantly more steeply.

The South African consumption profile - which includes both private and public consumption - is also quite different when compared to that of other countries in that there seems to be a relatively stronger correlation between labour income and consumption in South Africa. Consumption relative to peak labour income for children and young adults in South Africa generally falls within the first quartile of NTA countries, but rises into the top quartile for those roughly between the ages of 30 and 60 years. While per capita consumption in most NTA countries remains relatively stable or declines slightly for older individuals, there is a relatively strong decline in South Africa so that per capita consumption amongst 80 year olds, for example, is almost one-quarter below that of 60 year olds.

This continual and significant decline in total consumption amongst older cohorts suggests weaknesses in the institutions - whether public or private - that, in many other NTA countries, ensure that consumption amongst the elderly is maintained at levels comparable to those amongst prime working-age cohorts. This is not simply a cohort effect, driven by rising incomes over time. Even in countries where there have been very rapid rises in incomes (see, for example, the case of Taiwan discussed in Mason and Lee (2007)), the institutions that regulate the sharing activity within the NTA framework - specifically inter-household transfers and the public transfer system - are generally able to maintain elderly consumption levels. 
In combination, the labour income and consumption profiles determine the shape of the lifecycle deficit. The deficit is positive amongst the young and the elderly, but is negative (i.e. a surplus) amongst the prime working age cohorts. Overall, South Africa's surplus period lasts 30 years, between the ages of 30 and 59 years, which is broadly typical of NTA countries. The late rise in labour income delays the transition to surplus so that South Africa is one of the last countries to generate a lifecycle surplus. Similarly, by age 60, when South Africa returns to deficit, only three other NTA countries (Nigeria, Sweden and Uruguay) are still generating surpluses.

\section{The First Demographic Dividend}

As noted, the first demographic dividend is measured as the rate of change of the support ratio - the ratio of effective producers to effective consumers. Using the NTA age profiles for labour income and consumption and combining them with population projections by age, it is possible to calculate the support ratio and the first demographic dividend. There is one important caveat to note. Since the support ratio is calculated on the basis of a single labour income and a single consumption age profile, the demographic dividends calculated here are based on the assumption that these patterns (of labour income and consumption) are 'typical' and unchanging over time. In other words, in the context of labour income, for example, it is assumed that the structure of remuneration in an economy does not changes systematically over time, that labour force participation rates by age do not change and that unemployment rates do not change - or at least do not change in ways that would impact on mean labour income for any given age cohort. Insofar as this is not the case, the estimates presented below will be impacted.

Figure 2 presents estimates of the size of the first demographic dividend under various assumptions. South Africa is currently in a phase during which the demographic dividend is generally falling in magnitude. Although not shown in the figure, the estimates show that the demographic dividend has been positive since 1975 and peaked during the mid-1990s at just over one percentage point. Using the medium fertility variant - the baseline estimate for the purposes of this paper - the first dividend has declined since and, after an expected 20-year surge beginning soon after 2020, will turn negative and represent a drag on income growth from the mid-2040s onwards. Nevertheless, the magnitude of the first dividend for South Africa is in line 
with the experiences of many other middle-income countries. For the 2005-2010 period, the annual growth rate of the South African support ratio ranged between 0.15 and 0.40 percent, compared to an average of 0.4 percent for 12 upper-middle income countries for which there are NTA estimates (Mason and Lee, 2012, p.14). Individual estimates for these 12 countries ranged between 0.13 percent (Thailand) to 0.59 percent (Costa Rica) (Mason and Lee, 2012, p.14).

$<<<$ Figure 2 about here $>>>$

$\ll$ Figure 2: Estimates of the first demographic dividend for South Africa, 2005$2060>>>$

$\ll$ Source: Own calculations, National Transfer Accounts (2013); population estimates and projections from United Nations (2013b).

Notes: 1. Demographic dividend estimates have been smoothed by calculating the annual average growth rate of the support ratio over a six-year period (e.g. 20052010), allocating that value to the middle period (e.g. year 2007.5) and interpolating annual values using a quadratic polynomial. 2. Median age profiles for labour income and consumption are constructed using the median normalised value across the 34 countries for which data is available within each age cohort. Where countries have estimates for multiple years, only the most recent estimate is used. >>>

This late surge in the size of the first dividend is associated with the impact of HIV/Aids, which has severely impacted South African society. The rapid spread of the disease in South Africa means that the country has the world's third highest HIV prevalence (11 087 per 100000 in 2011) and the largest population living with HIV (5.6 million in 2011), and consequently life expectancy has fallen by five years to 58 years between 1990 and 2011 (World Health Organization, 2013). The spread of HIV/Aids has primarily been amongst working age cohorts and evidence points to particularly high prevalence amongst women between the ages of 20 and 40 years, and men between 30 and 44 years (although prevalence is generally lower amongst men). The result is a reduction in the size of the working age cohorts - adults aged 20 to 49 years accounted for half of all deaths in Southern Africa between 2005 and 2010, compared with 21 percent between 1985 and 1990 (United Nations, 2011, p. 20) - a rise in the dependency ratio and a decline in the support ratio as the number of 
effective producers declines more rapidly than the number of effective consumers. Beyond the impact of Aids-related deaths, the support ratio may fall as a result of the often extended periods of morbidity experienced by sufferers. At the same time, population growth slowed with downward pressure on the number of women of childbearing age within the population, as well as increased infant and child mortality related to mother-to-child transmission of HIV. The immediate effect of the pandemic is, then, to depress the support ratio by reducing the size of the working age population. Later, though, the support ratio is boosted by the slowing rate of growth amongst the elderly population as the cohorts most affected by the pandemic reach old age.

In terms of the formulation of the support ratio, there are three channels through which the first dividend can be impacted: through demography, through labour income and through consumption. Demography is central to the dividend - without demographic change, the dividend would not arise - and changes in our assumptions regarding demographic change can boost or depress the magnitude of the dividend. In the case of South Africa, lowered fertility compresses the period of the positive dividend, but generally increases the magnitude of the positive dividend in a given year. Conversely, higher fertility depresses the magnitude of the positive dividend, but extends the period of positive dividend beyond 2060. These effects are illustrated in Figure 2 by the low and high fertility variants respectively, which differ from the medium fertility variant by 0.5 children per woman.

Labour income is the second channel. As noted, South Africa's labour income profile exhibits a significant lag in increasing from zero, associated with low levels of employment amongst the youngest working age cohorts. One possibility is that the magnitude of the dividend could be increased if the country's labour market were functioning more efficiently and providing employment - and labour income - to more young people. This possibility is simulated in Figure 2 by combining the median normalised labour income profile across the 34 countries, including South Africa, for which there is data available, with South Africa's consumption profile and population projections.

Even though the simulated support ratio is higher than the baseline in every year, using the median NTA country labour income profile actually weakens the first 
demographic dividend: for the 2005-2060 period, the dividend is strengthened only during the first two years. This is true in the vast majority of years for all of the profiles derived from various categorisations of NTA countries. ${ }^{2}$ Estimates for the period 1950 to 2100 reveal that the median labour income profile only improves the dividend between 1950 and the early 1980s, and for a few years during the mid2000s. Considering the labour income profiles presented in Figure 1, one can see that this somewhat surprising outcome is the result of lowering mean per capita labour income amongst older working-age cohorts, whose numbers were growing relatively slowly until around 1990, by using the median profile. ${ }^{3}$

The third channel is consumption. The shape of the South African consumption profile is unusual in the significant decline that occurs amongst older cohorts. What is the impact of this pattern of consumption on the support ratio and the magnitude of the first dividend? First, using the median NTA country consumption age profile in combination with the original labour income profile lowers the support ratio relative to the baseline estimate in each year. Between 2005 and 2060, the average support ratio under the medium fertility variant is 0.580 , compared to 0.497 using the median consumption profile. The simulation of the dividend suggests that the current pattern of consumption depresses the first dividend: the median NTA country consumption profile generates a dividend that is greater than the baseline dividend in every year between 2005 and 2060. Further, this finding - that the current consumption profile depresses the first demographic dividend - holds true relative to all geographical, income level and percentile-based categorisations of the NTA countries.

To what degree is it realistic to impose a particular labour income or consumption profile on the data for South Africa? In some sense, this is a simulation of a very different reality. It is extremely improbable (if not impossible) that a different labour

\footnotetext{
${ }^{2}$ Median cross-country profiles were calculated by geographical location (Africa; Latin America and the Caribbean; Europe, US and Australia; South-East Asia; East Asia; South Asia), and by per capita income level (high, upper middle, lower middle and low income), while profiles were calculated at the 25th, 50th and 75th percentile of normalised values across all NTA countries.

${ }^{3}$ Interestingly, although not shown here, even if the South African labour income profile is changed only to reflect the median profile from age zero to age 45 , the simulated demographic dividend remains below the baseline estimate. Here again, the support ratio is higher in each year than that of any of the other estimates presented here.
} 
income profile, for example, would be consistent with the estimated consumption profile, given the structure of transfers and asset-based reallocations. However, the simulation is only concerned with the left-hand side of the NTA identity (equation 1). Allowing the right-hand side of the identity to adjust means that, as long as the aggregate labour income and consumption flows are unaffected, the new labour income profile is consistent with the original consumption profile (or vice versa). Nevertheless, this could potentially entail vastly different flows to finance the lifecycle deficit than is estimated using the actual country data; flows that may not be feasible given individual preferences, local customs and norms, and institutional arrangements. What is important to note is that these simulations do not take into account potential impacts on household formation. Even though the various profiles are constructed on the basis of household survey information, they are abstracted from the household data and the effects on household formation are not possible to predict within this framework.

Overall, the estimates of South Africa's first demographic dividend confirm a positive impact on per capita incomes from 2005 until around 2040, except for a slight negative impact under the high fertility variant during the early 2020s. This is an important finding, suggesting a significant degree of robustness to potential changes to the underlying labour income and consumption profiles. The simulations do suggest, though, that the weak sharing mechanisms within South African society may hold a non-negligible cost for per capita income growth over time. This is a somewhat unexpected finding, but is consistent with the argument that is increasingly being made that inequality is acting as a brake on South African economic growth.

\section{The Second Demographic Dividend}

The first demographic dividend arises almost mechanically as the support ratio rises while the boom generations born during the initial stages of the demographic transition enter the working-age population and come to dominate overall population structure. However, once a new steady state is achieved at low fertility and low mortality, the boost to per capita incomes provided by the first dividend dissipates and it is quite possible that per capita incomes may return to pre-transition levels. While the first demographic dividend is a transitory phenomenon, the second dividend has the potential to permanently raise incomes and consumption (Mason and Lee, 2007, 
p.128). This occurs through the accumulation of capital - financial and physical on the one hand, and human on the other - driven by the fact that "a longer horizon for the individual makes investing in education more worthwhile and makes saving for retirement essential" (Bloom and Canning, 1999, p.1).

\subsection{Savings}

Bloom et al. (2003, p.39) identify savings as one of the mechanisms through which the demographic dividend arises, although they do not differentiate between the two dividends. As populations age and the support ratio begins to decline, asset accumulation represents the only way through which elderly cohorts are able to maintain their levels of consumption without compromising the consumption of younger generations. The alternative is to rely on future generations to transfer resources to the elderly in order to support their consumption, either through the familial transfer system or through public systems such as unfunded pension schemes (or, using a South African example, the non-contributory state old age pension). The process of generating a 'claim' against future generations is referred to as transfer wealth accumulation (Mason and Lee, 2006, p.14), which is matched by 'transfer debt' held by future generations.

While technically allowing the elderly to maintain consumption levels, these two processes are quite different in terms of their implications for the second dividend. Accumulating assets requires saving during the working ages and, as a result, consumption is lowered during these ages. These accumulated financial assets, under appropriate institutional arrangements, can be used in two ways: they can either be invested in the domestic economy, leading to capital deepening and an increase in productivity (and, potentially, labour income); or they can be used to accumulate foreign assets, giving rise to asset income inflows from the rest of the world. Accumulating transfer wealth, on the other hand, requires no immediate sacrifice of consumption, but may compromise the future consumption of all generations if the burden on the working age population becomes too large. Critically, though, without any savings, no assets are accumulated and no second demographic dividend is realised.

A country's chances of enjoying the second dividend are, therefore, linked to the 
institutional context that governs the support of the elderly. Countries that rely more on transfers - public or private - to finance the consumption of the elderly will find themselves in a weaker position to benefit from a second demographic dividend that those that rely more on assets. This distinction is possible to make using NTA estimates, relying on the right-hand side of the NTA identity (see equation 1). In terms of this identity, the lifecycle deficit is financed through the sum of public and private transfers and asset-based reallocations.

In South Africa, the elderly are found to be heavily reliant on asset-based reallocations to fund the lifecycle deficit (Table 1). In fact, for the population aged 65 years and older, asset-based reallocations (including asset income and asset disposals) more than fully fund the deficit, with the rest - equivalent to 28.0 percent of the aggregate lifecycle deficit - being transferred to younger cohorts. This result, although contrary to the common view of the elderly as dependent on their children for support, is in line with evidence that suggests that, amongst poorer communities, households are forming around recipients of the state old age pension in response to high unemployment (Klasen and Woolard, 2009), although the figures presented here are more likely to be driven by wealthier individuals within the elderly population. This reliance on asset-based reallocations is observed for both younger and older subgroups within the elderly population. In contrast, with the elderly paying taxes as well as receiving benefits, the public transfer system overall plays only a very small role in financing the deficit amongst those aged 75 years or more ( 8.0 percent), while for those under 75 years the public transfer system represents a drain on their resources.

Table 1: Financing the Lifecycle Deficit, 2005

\begin{tabular}{|l|r|r|r|}
\hline & $65-74$ years & $75+$ years & $65+$ years \\
\hline Financing of the Aggregate Lifecycle Deficit (percent share) \\
\hline Transfers & -34.9 & -11.5 & -28.0 \\
\hline Public transfers & -4.7 & 8.0 & -1.0 \\
\hline Private transfers & -30.2 & -19.5 & -27.0 \\
\hline Asset-based reallocations & 134.9 & 111.5 & 128.0 \\
\hline Share of population (percent) & & & \\
\hline
\end{tabular}




\begin{tabular}{|l|r|r|r|}
\hline 2005 & 3.1 & 1.3 & 4.5 \\
\hline 2060 & 8.2 & 5.2 & 13.4 \\
\hline
\end{tabular}

Source: Own calculations; population estimates and projections from United Nations (2013b).

Notes: 1. Shares may not add up to 100 in rows due to rounding. 2. Population estimates are based on the medium fertility variant.

This relatively favourable pattern of support for the consumption of the elderly is important, given the rapid growth in the elderly population that is expected between 2005 and 2060. Under the medium fertility variant, the elderly population (65 years and older) is expected to triple as a proportion of the total population, from 4.5 percent to 13.4 percent. Growth amongst those aged 75 years and above is expected to be even more rapid. These growth rates are important because, apart from behavioural changes that raise aggregate savings (increased life expectancy stimulates higher saving), there is also a compositional effect as a growing proportion of the population fall within those cohorts with the greatest savings levels (i.e. those near or past retirement). It is therefore expected that demand for lifecycle wealth in South Africa will grow rapidly over this period, particularly once greater longevity and the need to make provision for longer periods of retirement is internalised by working age cohorts.

From the perspective of a strong reliance on assets to fund the consumption of the elderly, South Africa seems well placed to enjoy the second dividend. The country possesses a sophisticated and highly regarded financial system - South Africa is currently ranked third globally in terms of financial market development (World Economic Forum, 2013) - that should be able to facilitate and encourage saving and efficient allocation of capital. Further, the current move towards the introduction of mandated retirement savings for the employed is likely over time to strengthen the reliance of the elderly on accumulated assets, by both encouraging asset accumulation and preserving accumulated assets as workers change jobs. An added benefit may also be a reduced reliance by the elderly on the social grant system. However, the ability of the population to accumulate assets in preparation for retirement is entirely dependent on the functioning of the labour market. 
The South African labour market, though, remains distorted by the effects of apartheid. Inequalities in the provision of education by race group - in terms of both quality and quantity - has resulted in a skewed distribution of skills in favour of the White minority in particular. At the same time, the economy's growth path for much of the past four decades has been capital- and skills-intensive, depressing the demand for less-skilled workers while maintaining shortages in high-skilled occupations (Bhorat and Hodge, 1999; Rodrik, 2008). This mismatch between labour supply and demand is most starkly illustrated in unemployment rates by educational attainment: in 2014, the expanded unemployment rate for those with an incomplete secondary education is more than five times that of those with university degrees (41.8 percent compared with 7.6 percent) (own calculations, Statistics South Africa, 2014b).

The skills mismatch exists alongside significant youth and long-term unemployment, with these high rates of unemployment amongst younger cohorts explaining the late rise in labour income in South Africa and the late transition to surplus. An extended period of economic dependence amongst young people is an immediate concern in terms of the additional burden placed on older cohorts, directly as the source of private transfers and indirectly as the ultimate source of public transfers. It also represents a longer-term concern through the 'wage scar' that youth unemployment may cause. Although no estimates of a youth unemployment wage scar exist for South Africa, Gregg and Tominey (2004, p.2), for example, find that youth unemployment imposes a wage scar of around 12 percent to 15 percent at age 42 in Great Britain, although it is lower if repeat unemployment spells are avoided. Youth unemployment, therefore, negatively impacts future earnings potential, constraining the ability of prime working cohorts to generate sufficient future surpluses and limiting the scope for saving and making transfers to other cohorts.

\subsection{Human Capital Accumulation}

Human capital accumulation is the second channel through which the demographic dividend may arise. The extent of a country's investment in its younger generations is often judged by measures such as the proportion of GDP spent on education (or health). However, these measures are affected by countries' demographic structures, making accurate cross-country comparisons difficult. For example, in 2010, South Africa spent 6.0 percent of GDP on education, placing it between Tanzania (6.2 
percent) and the Netherlands (6.0 percent) amongst the top 30 countries for which there is data (World Bank, 2013). However, each country has very different population age structures, making these figures almost meaningless on their own.

The mechanism through which human capital accumulation may give rise to a second demographic dividend is through the trade-off between the quantity and the quality of children within a budget constraint (Becker and Lewis, 1973; Willis, 1973; Becker and Barro, 1988). As fertility declines, parents are able to devote greater resources to the human capital accumulation of their children. This relationship is confirmed by Lee and Mason (2010) using synthetic cohort estimates of human capital spending public and private spending on education from age 0 to age 26, and public and private spending on health from age 0 to age 17 - relative to peak labour income derived from NTA data for 19 countries. They find a significant negative relationship between human capital spending and fertility and an elasticity of -1 , implying a trade-off between the number of children and spending on human capital that keeps total spending roughly constant (Lee and Mason, 2010, p.167).

Updated estimates expanding the number of countries and adjusting the age range over which education spending is aggregated to three to 26 years reconfirm a significant negative relationship between the total fertility rate and human capital spending (Figure 3). Moreover, spending on human capital accumulation in South Africa is consistent with this cross-country pattern, given its level of fertility: South African lifetime human capital spending per child is equivalent to 285 percent of peak labour income, with its total fertility rate at 2.7 children per woman. While this level of spending is slightly lower than that of NTA countries in Latin America and the Caribbean with similar fertility rates, it is slightly higher than that of similar NTA countries in South and South-East Asia.

$$
<<\text { Figure } 3 \text { about here }>>>
$$

$\ll<$ Figure 3: Lifetime human capital spending and fertility $>>>$

$\ll$ Source: Own calculations, National Transfer Accounts (2013); update of estimates presented in Lee and Mason (2010).

Notes: 1. Lifetime human capital spending is the sum of all per capita spending on 
education between the ages of three and 26 years and all per capita spending on health between the ages of zero and 17 years, using synthetic cohorts. All values are expressed as proportions of peak labour income (mean per capita labour income between the ages of 30 and 49 years). 2. Where countries have estimates for multiple years, only the most recent estimate is used. 3. The curve represents the predicted relationship between TFR and human capital spending based on a log-log regression on the sample of countries, excluding Nigeria (the high TFR, high human capital spending outlier). >>

The data therefore indicates that South Africa is investing in human capital at a level that is in line with international experience - at least as far as the group of NTA countries is concerned - suggesting that this prerequisite for reaping the second demographic dividend is being met. Despite this, the evidence suggests that this investment may fail to unlock the second dividend. The chief reason for this is the persistence of deep inequalities in the quality of service provision in the areas of education and health during the post-apartheid era. Social services were characterised by a fractured delivery system under apartheid, with separate government departments overseeing education and health services depending on race and location. Thus, for example, by the early 1990s, there were 19 departments responsible for education in South Africa (Jansen and Taylor, 2003, p.9). Combined with racially differentiated fiscal allocations to education and health (Van der Berg, 2001), this resulted in wide disparities in the quality of these services that have persisted into the post-apartheid era (Van der Berg, 2007). This persistence is likely at least partly due to the widely varying initial conditions faced by the new provincial departments, with some provinces particularly burdened by the incorporation of dysfunctional departments inherited from the previous political system, while at the same time often having to provide services to some of the country's poorest, most deprived and least urbanised areas.

In terms of education, the result is the existence of a bimodal distribution of schools in terms of performance (see, for example, Van der Berg, 2007; Spaull, 2012). Spaull (2012, p.4) notes that this bimodality "can be seen as early as Grade 3 ... and remains unabated until the national school leaving exam", and is visible when dividing schools 
by wealth quartiles, school language and apartheid-era education department. Van der Berg (2007, p.859) estimates that while Africans accounted for 83 percent of the Grade 12 cohort in 2003, they accounted for only 71 percent of passes, 22 percent of higher grade mathematics passes (i.e. with a 50 percent mark or better), and just eight percent of passes with an A-aggregate mark (average over all subjects of at least 80 percent). Such inequalities in education reproduce inequality in the labour market and raising quality in former black schools, in particular, must be a policy priority.

Not only are a large number of schools unable to achieve satisfactory results relative to the national curriculum, South African schools also perform poorly when compared internationally: "South African schools generally perform at an even lower level than most of their African counterparts, despite greater South African resources, less acute poverty and more educated parents" (Van der Berg, 2007, p.854). Again, this demonstrates some of the inequalities within the system, but also points to systemic failures within education that do not bode well in an era of globalisation, international trade and competition for foreign direct investment.

The process of equalisation of spending across race groups - or, rather, the delinking of per capita fiscal allocations from race - has tended to fuel perceptions of falling quality in the public health and education systems. Those who can afford to move to private sector provision of healthcare, in particular, have tended to do so. In education, while this trend exists, it has been dampened by provisions that allow schools, through school fees and fund-raising, to finance the hiring of additional teachers, for example. The private healthcare system is well-resourced, but covers only a fraction of the country's population. It is estimated that approximately 17 percent of South Africans are covered by private medical schemes, while almost 30 percent of South Africans report using private healthcare services at the time of their last visit (Blecher et al., 2011, p.32). At the same time, Blecher et al. (2011, p.33) estimate that, at the time, private financing accounted for roughly half of total health spending since the 2008/09 fiscal year. $\square$ Thus, while South Africa's spending on human capital accumulation is in line with expectations given its fertility rate, inequalities in outcomes are pervasive and undermine the country's ability to harness the second dividend.

\section{Discussion}


On the basis of South Africa's NTA data, the evidence suggests that the country has already passed through a significant proportion of its first demographic dividend. Demographic change is estimated to have contributed positively to per capita income growth since 1975 and this is expected to continue until at least 2040, except under a high fertility assumption. For much of the period since 1975, the South African policy context was largely hostile to the demographic dividends: large sections of the population were denied access to quality education and health services, and were actively excluded from employment opportunities in line with apartheid's race-based policies. Further, apartheid's spatial policies forced large proportions of the African working age population into remote rural areas that lacked the economic basis to provide sufficient employment. While these policies were abandoned by the time of the democratic transition, their effects continue to be felt.

The demographic dividends represent potential benefits that may accrue to ageing societies, rather than automatic windfalls. With only perhaps three decades in which South Africa can still potentially experience a positive first demographic dividend, has the opportunity been lost? More importantly, has South Africa squandered its chance to benefit from a second demographic dividend? The need for appropriate policy interventions is clear: "[the] benefits of the 'demographic dividend' require that desired changes in labor supply, savings, and educational attainment actually come about in practice" (Bloom and Canning, 1999, p.33). This point is reiterated by Mason and Lee (2006, p.15), who note that both the first and the second demographic dividends "depend on effective complementary economic policy".

Is a policy environment conducive to the realisation of the demographic dividend in place in South Africa? It would seem the answer is not yet. The weakness in the labour market and continued problems in the provision of quality education to the broader population highlighted above point to the fact that South Africa will be hard pressed to fully capture the dividend as current inequalities are reproduced in younger generations. Moreover, the economy continues to grow in such a way as to reduce demand for South Africa's abundant supply of relatively unskilled labour, while skills shortages persist, with negative consequences for levels of wage inequality.

Inequalities in terms of quality of education are particularly concerning and have farreaching consequences. As noted by the World Bank (2012, p.xi), "the disadvantages 
conferred by unequal opportunities in education earlier in life are an increasingly consequential stumbling block to the social and economic mobility of individuals, for whom having a job is crucial". These effects of these inequalities are compounded by inequalities in quality of health service provision and the burden of disease, as well as in access to housing, sanitation and water supplies, which all play a role in determining wellbeing.

From a policy perspective, the key constraint is one of time. The policy priorities for maximising the benefit from the demographic dividends should be formulated in terms of South Africa already having transitioned through the first half of its first dividend period. In this respect, policy should prioritise economic growth and should attempt to fundamentally shift the structure of production towards greater labour intensity, particularly in relation to low-skilled workers. Without such a focus, significant proportions of working-age cohorts will remain effectively 'unemployable'. The pursuit of a more labour-intensive growth path represents a critical shift in South Africa's economic trajectory and is fundamental to the creation of employment on the required scale. Without this shift, the economy will remain unable, even at relatively high rates of growth, to absorb new labour market entrants into employment in sufficient numbers, representing a binding constraint on both demographic dividends.

Broad educational and health policies may suffer from long lead times, but there may be scope for targeted interventions particularly relating to post-secondary nonuniversity education, as well as artisan training and apprenticeships that would have shorter lags. Health policy should continue to address the prevention and treatment of diseases such as HIV/Aids and tuberculosis, which will help reduce the effective dependency ratio by reducing morbidity amongst working age cohorts.

The short timespan within which South Africa can still benefit from the dividend should not, however, shift efforts away from the systemic improvement of education (and health service) quality and the efficiency of resource use in these sectors. The benefits associated with such policies may take time to materialise but, even in the case of a steady state population, could help raise incomes in the longer-term.

On a positive note, the NTA estimates underlying the calculation of the demographic 
dividend are characteristic of the 2005 pattern of economic flows, which in turn are determined by the prevailing economic circumstances, social and cultural norms, and institutional arrangements. Improvements in, for example, the employment rate of young people that do not negatively impact on older working ages would benefit the size of the first dividend and, subsequently, may improve the prospects for the second. Importantly, the simulations presented in Figure 2 confirm the importance of the structure of consumption in generating the first dividend by revealing the concentration of high consumption levels amongst older working aged cohorts negatively impacts on the size of the dividend. Given South Africa's history, it is not clear that the country possesses the social capital necessary to effectively address this pattern of consumption through the public transfer system. Nevertheless, it seems likely that improving the labour market prospects of the youth may benefit both their own consumption levels, as well as those of elderly cohorts who are currently making significant downward transfers.

One area that the analysis has been unable to probe properly - and one that has surfaced repeatedly - is the impact of inequality on the NTA profiles. This is particularly important in the context of two key issues: first, income is highly correlated with race and, second, South Africa's four main race groups find themselves at different points in the demographic transition. Importantly, the group that has traditionally had the highest per capita income, namely Whites, is already experiencing significant population ageing, while Africans, with the lowest per capita incomes, have been the slowest to begin the demographic transition.

In practice, what this means is that patterns of resource flows are likely to be dominated by flows linked to wealthier groups who also tend to have older age structures. For example, the high degree of reliance of the elderly on asset-based reallocations to finance the lifecycle deficit is driven largely by Whites, who already have a relatively old age structure. However, future ageing will be driven by the rest of the population, whose elderly cohorts are currently far more reliant on state transfers than their White counterparts. The link between income and stage within the demographic transition means that projections may be exposed to an additional compositional effect as wealthier groups become relatively smaller within age cohorts over time. Admittedly, this may be the case in many countries around the world, but 
given the extreme levels of inequality in South Africa, the impact on the estimates is likely to be larger. The analysis of inequality within the context of NTA is a new area of research and is an avenue that we will be pursuing for South Africa.

\section{Conclusion}

South Africa's demographic transition is well underway and estimates suggest that the country has already progressed through at least half of the period during which the first demographic dividend is expected to be positive. Despite the opportunity presented by the changing structure of the population, policy under apartheid has largely weakened the country's ability to capture the dividend, by thwarting human capital investment and preventing the optimal employment of the working-age population.

Has South Africa missed out on the demographic dividends? Arguably, given the significant policy distortions under apartheid, the portion of the first demographic dividend that has been experienced thus far has been sub-optimal by a considerable margin. And, despite various improvements post-1994 in terms of access to services, housing, telecommunications and electrification, progress has been weak in the three areas most critical to the demographic dividends, namely education, health and the labour market.

The simulations of the first demographic dividend suggest that, even under relatively widely varying assumptions relating to fertility and the patterns of labour income and consumption, the first demographic dividend will remain positive another three decades at least. Lowered fertility is expected to boost the magnitude of the dividend, but will also slightly compress the remaining period of positive dividend. What seems to make the strongest impact on the first dividend, under the medium fertility assumption, is a profile of consumption that is not as strongly correlated with that of labour income. In particular, the simulation uses a profile that has slightly higher consumption relative to peak labour income amongst both children and the elderly, at the expense of those in the prime working ages. It is not clear that it is possible to effect such a shift in the consumption profile through redistributive policy, but it does seem that addressing youth unemployment may go some way towards achieving such a shift. $\square$ The mechanisms that underlie the attainment of the second demographic 
dividend have relatively long lags and, as a result, "the foundation for the second demographic dividend occurs early in the demographic transition" (Mason and Lee, 2007). While the NTA allows for a more nuanced analysis of a society's investment in human capital formation through both public and private spending on education and health, it is argued that the link between spending and outcomes, or quality, is relatively weak in South Africa, with wide variation across standard correlates of disadvantage in the South African context. Urgent and concerted policy effort is therefore required if South Africa is not to miss out on the second dividend. $\square$ Pool (2007, p.34) argues that the key to maximising the second dividend is "the successful exploitation of the first demographic dividends. The developed countries that long ago passed through their dividend phase ... will vary in the degree to which they capitalised on these trends, and thus whether they are also likely to be the beneficiaries of the associated second dividend. Many will have squandered this opportunity." With South Africa halfway through its first dividend period and still suffering from the consequences wrought under apartheid, it will hopefully not have squandered its opportunity too.

\section{Acknowledgements:}

The author would like to thank Ronald Lee and Andrew Mason for their suggestions and comments on previous related papers, as well as other members of the NTA network for various interactions and discussions. While they can not all be thanked individually here, the work of the more than 30 teams responsible for constructing the NTA estimates for their specific countries is gratefully acknowledged.

Funding for this research was received from the International Development Research Centre (IDRC) through the African Economic Research Consortium (AERC; AERC Grant No. RC09509), and from the Bill and Melinda Gates Foundation through the Foundation for Economics Education (FEE; FEE Grant No. HC13052ZN).

\section{Bibliography}


Becker, G. S. and Barro, R. J. (1988), 'A reformulation of the economic theory of fertility', $Q J$ Econ 103(1), 1-25.

Becker, G. S. and Lewis, H. G. (1973), 'On the interaction between the quantity and quality of children', J Polit Econ 81(2, Part 2), S279-S288.

Bhorat, H. and Hodge, J. (1999), 'Decomposing shifts in labour demand in South Africa', S Afr J Econ 67(3), 349-380.

Blecher, M., Kollipara, A., De Jager, P. and Zulu, N. (2011), 'Health financing', in South African Health Review, Health Systems Trust, Durban, South Africa, pp. 2948.

Bloom, D. E. and Canning, D. (1999), 'Economic development and the demographic transition: The role of cumulative causality', Consulting Assistance on Economic Reform II Discussion Paper 51.

Bloom, D. E., Canning, D. and Malaney, P. N. (2000), 'Population dynamics and economic growth in Asia', Popul Dev Rev 26(Supplement: Population and Economic Change in East Asia), 257-290.

Bloom, D. E., Canning, D. and Sevilla, J. (2003), The Demographic Dividend: A new perspective on the economic consequences of population change, RAND Corporation. $\square$ URL: http://www.rand.org/pubs/monograph reports/MR1274.

Gregg, P. and Tominey, E. (2004), 'The wage scar from youth unemployment', CMPO Working Paper Series No. 04/097.

Jansen, J. and Taylor, N. (2003), Educational change in South Africa 1994-2003: Case studies in large-scale education reform, Country Studies, Education Reform and Management Publication Series Vol. II No.1, World Bank, Geneva.

Klasen, S. and Woolard, I. (2009), 'Surviving unemployment without state support: Unemployment and household formation in South Africa', J Afr Econ 18(1), 1-51.

Lee, R. (1994), The formal demography of population aging, transfers and the economic life cycle, in S. P. L Martin, ed., 'The Demography of Aging', National Academy Press, pp. 8-49. 
Lee, R. and Mason, A. (2010), 'Fertility, human capital, and economic growth over the demographic transition', Eur J Popul 26(2), 159-182.

Lee, R. and Mason, A. (2011), Population aging and the generational economy: A global perspective, Edward Elgar and IDRC, Cheltenham, UK, and Ottawa, Canada.

Mason, A. and Lee, R. (2006), 'Reform and support systems for the elderly in developing countries: capturing the second demographic dividend', GENUS LXII(2), $11-35$.

Mason, A. and Lee, R. (2007), Transfers, capital and consumption over the demographic transition, in N. O. Robert Clark and A. Mason, eds, 'Population Aging, Intergenerational Transfers and the Macroeconomy', Edward Elgar, Cheltenham, UK, pp. 128-162.

Mason, A. and Lee, R. (2011), Population aging and the generational economy: Key findings, in 'Population Aging and the Generational Economy', Edward Elgar Publishing, Inc. and the International Development Research Centre, Cheltenham, UK, and Ottawa, Canada, pp. 3-31.

Mason, A. and Lee, R. (2012), Demographic dividends and aging in lower-income countries. National Transfer Accounts Working Paper No. 12-01. December. URL: http://www.ntaccounts.org/.

National Transfer Accounts (2013), 'NTA Database', Online database. URL: http://www.ntaccounts.org/.

Pool, I. (2007), 'Demographic dividends: Determinants of development or merely windows of opportunity', Ageing Horizons 7, 28-35.

Rodrik, D. (2008), 'Understanding South Africa's economic puzzles', Econ Transit 16(4), 769-797.

South African Reserve Bank (2013), Quarterly Bulletin Online Statistical Query, Online database. $\square$ URL: http://www.reservebank.co.za/

Spaull, N. (2012), 'Poverty and privilege: Primary school inequality in South Africa', Stellenbosch Economic Working Papers No. 13/12. 
Statistics South Africa (2006), Labour Force Survey (September 2005), Dataset. Pretoria: Statistics South Africa.

Statistics South Africa (2014a), Poverty trends in South Africa: An examination of absolute poverty between 2006 and 2011, Report No. 03-10-06, Statistics South Africa, Pretoria.

Statistics South Africa (2014b), Quarterly Labour Force Survey (2014Q1), Dataset. Pretoria: Statistics South Africa.

United Nations (2011), World Population Prospects: The 2010 Revision, Volume I: Comprehensive Tables, ST/ESA/SER.A/313, United Nations, Department of Economic and Social Affairs, Population Division, New York.

United Nations (2013a), Measuring and Analysing the Generational Economy: National Transfer Accounts Manual, United Nations, Population Division, Economic and Social Affairs, New York.

United Nations (2013b), World Population Prospects: The 2012 Revision, Department of Economic and Social Affairs, Population Division. $\square$ URL: http://esa.un.org/unpd/wpp/index.htm.

Van der Berg, S. (2001), 'Trends in racial fiscal incidence in South Africa', S Afr J Econ 69(2), 243-268.

Van der Berg, S. (2007), 'Apartheid's enduring legacy: Inequalities in education', $J$ Afr Econ 16(5), 849-880.

Willis, R. J. (1973), 'A new approach to the economic theory of fertility behavior', $J$ Polit Econ 81(2, Part 2), S14-S64.

World Bank (2012), South Africa economic update: Focus on inequality of opportunity, Issue 3. World Bank: Washington, DC.

World Bank (2013), World Development Indicators, Online database. URL: http://data.worldbank.org/data-catalog/world-development-indicators.

World Economic Forum (2013), The Global Competitiveness Index data platform, 
Online database. $\square$ URL: http://www.weforum.org/issues/competitiveness-0/gci2012data-platform/

World Health Organization (2013), Global health observatory data repository, Online database. URL: http://apps.who.int/gho/data/. 


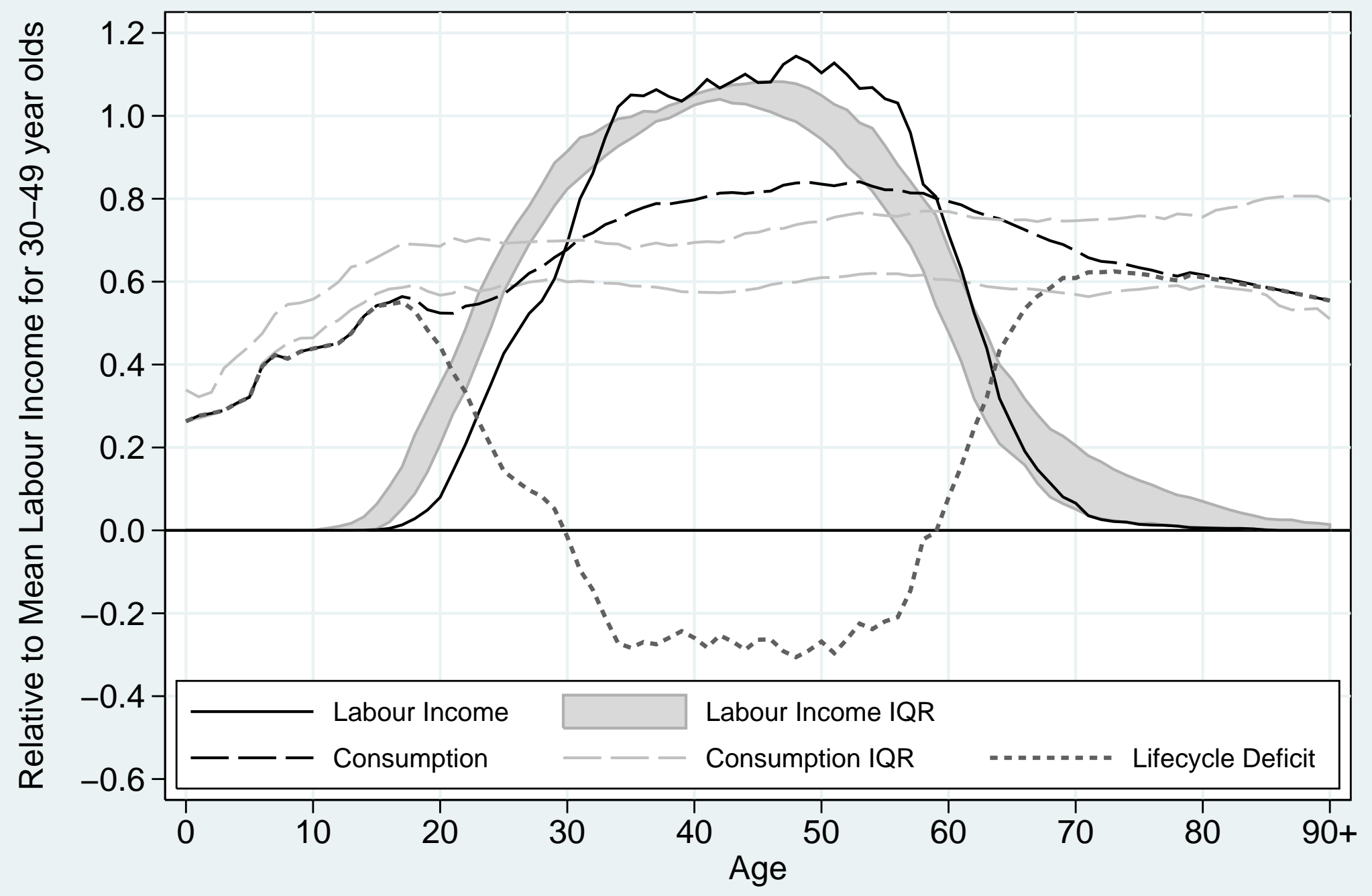




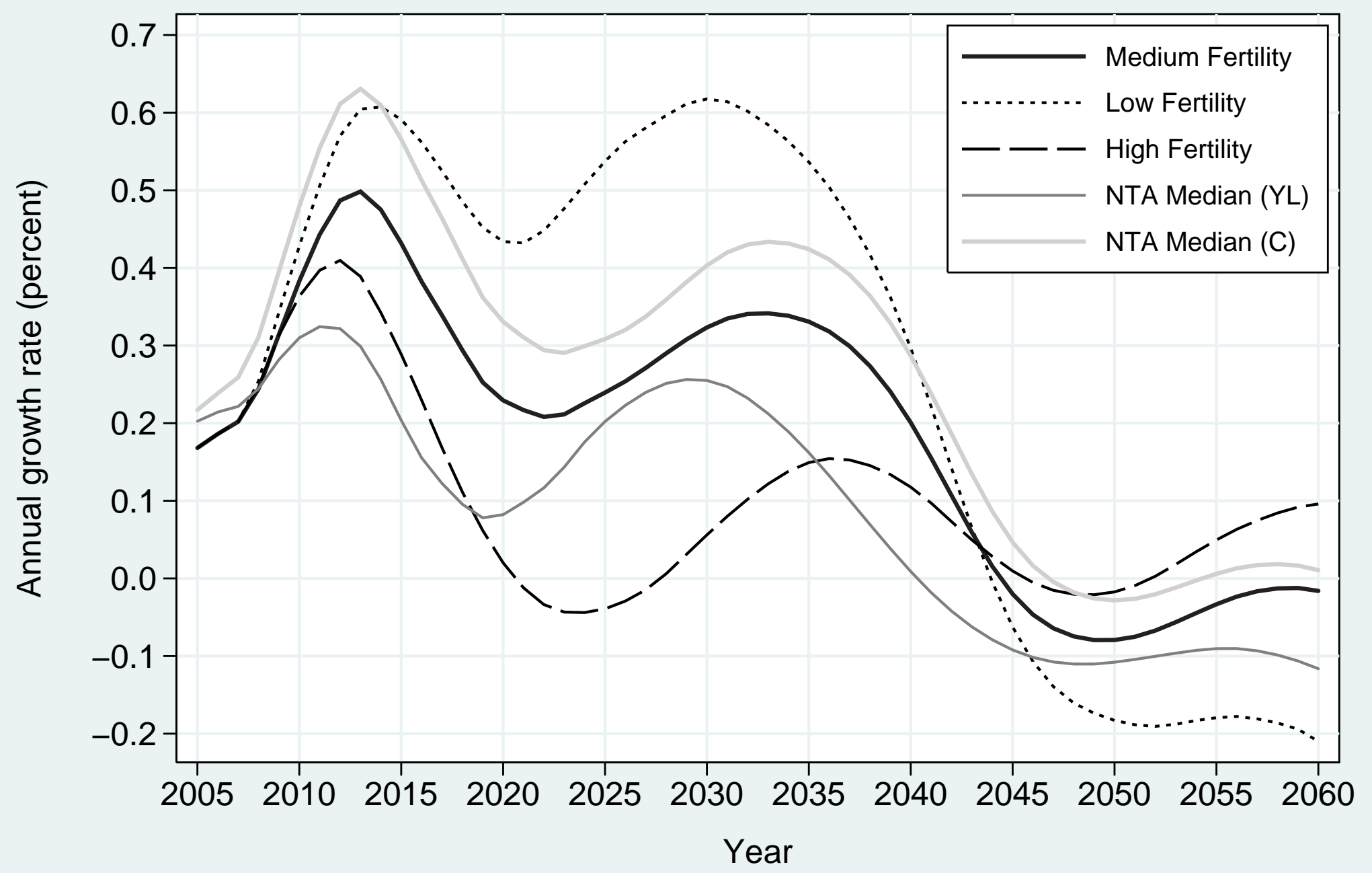




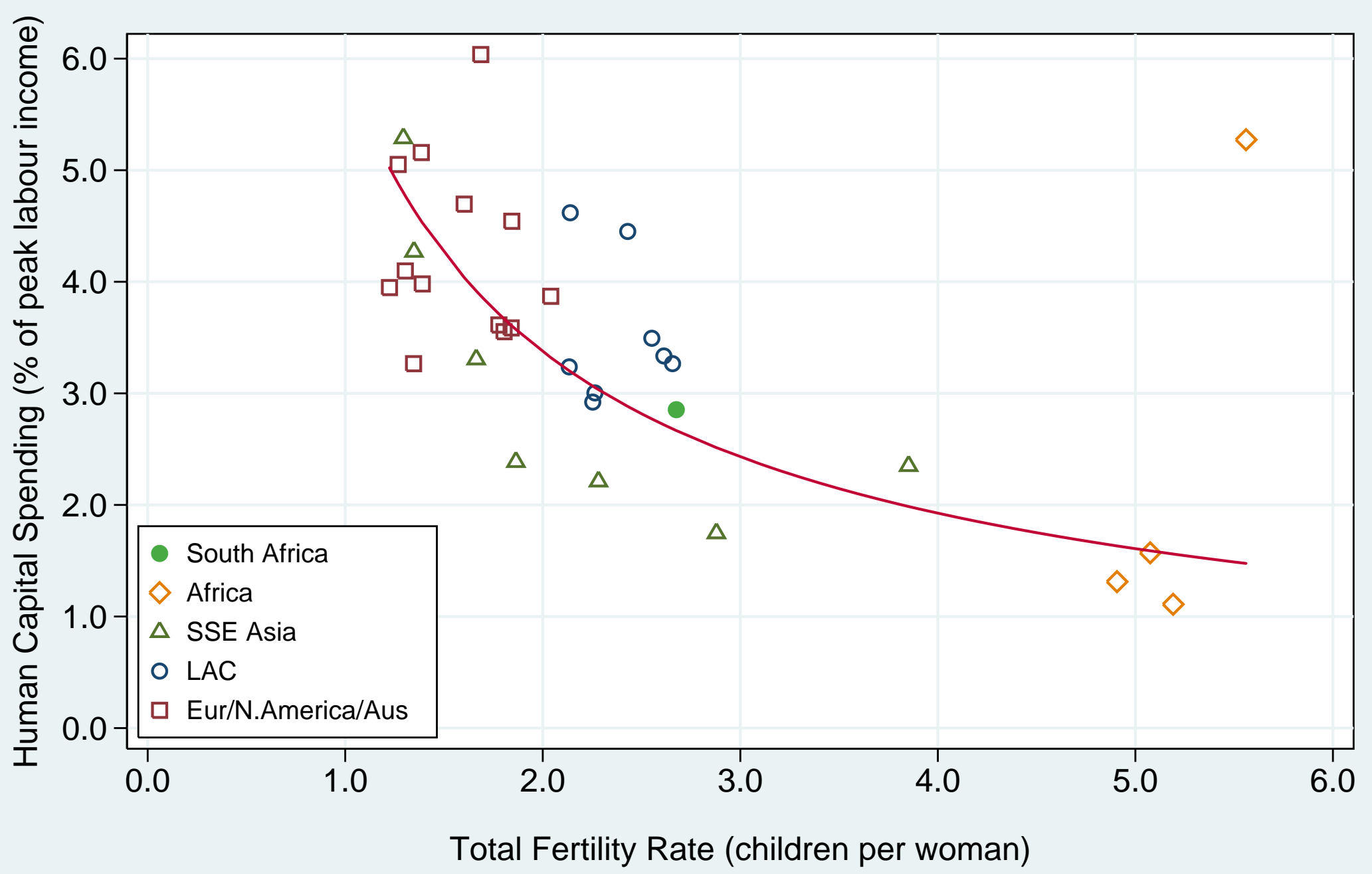

